\title{
Hardening of Gold-Based Dental Casting Alloys
}

\author{
INFLUENCE OF MINOR ADDITIONS AND THERMAL AGEING
}

\author{
Jean-Jacques Labarge \\ Faculté d' Odontologie, Université Claude-Bernard, Lyon, France
}

and Daniel Tréheux and Pierre Guiraldenq

Laboratoire de Métallurgie Physique, Ecole Centrale de Lyon, Ecully, France

\begin{abstract}
The ordering and precipitation phenomena responsible for hardening of gold-based alloys used in jewellery and in dentistry are complex and by no means fully understood. The authors of this article review these effects and present evidence which indicates that separation of gold-zinc intermetallic phases may contribute to such hardening in certain alloys.
\end{abstract}

Investment casting is the method of choice for the fabrication of both small and large dental prostheses, because of the precision which can be achieved using it. Whether a prosthesis will be functional, however, depends on the properties of the alloy from which it is cast. Ideally, this must not only be amenable to investment casting without difficulty, but it must also be resistant to the oral environment and biochemically and mechanically compatible with it.

There are currently three main types of dental alloys available to the practitioner: gold-based alloys, nickel-chromium alloys and chromium-cobalt alloys. Gold-based alloys, in spite of their higher cost, are preferred by dentists. Their advantages over competitors include their moderate melting temperatures, the precision with which they can be cast, their outstanding corrosion resistance and freedom from irritant or other biochemical effects. Their main disadvantage relates to their hardness. In contrast to the base metal alloys which suffer from excessive hardness and can cause detrimental wear of the teeth opposite the appliance, gold-based dental alloys display only limited hardness. For this reason, research on them has aimed at improving this property, either by the introduction of minor additions or by thermal ageing or both. Since Coleman's initial work (1), on which the first American Dental Association (ADA) specifications were based, casting alloys for conventional prosthesis have been much improved, notably by Wise (2) and Nielsen and Tucillo (3).

\footnotetext{
ADA Dental Casting Alloys

Specifications (4) for the composition and physical properties of gold casting alloys drawn up by the
}

ADA (Table I) have gained almost universal acceptance and constitute convenient terms of reference. The specifications distinguish between 4 types of alloys, all based on the gold-silver-copper system. Table I shows that the primary criterion for classification is mechanical properties as reflected by hardness. For each restoration a type of alloy with appropriate mechanical properties can be chosen. Thus, Type I is for simple inlays, Type II for composite inlays and Type III for crowns. Type IV is intended for highly stressed or large structures such as one-piece partial dentures.

\section{Composition}

It is not possible to associate each ADA alloy type with a separate range of composition. There is an overlap between the ranges allowed by the specifications for the major constituents (gold + platinum group metals, silver and copper) in the different types. For minor constituents, the percentages vary from zero to fairly high levels. It is therefore theoretically possible to have alloys of different types with identical compositions, the required mechanical properties being obtained by suitable heat treatments. However, Table I shows that in passing from Type I to Type IV the gold + platinum group metals contents decrease while the silver and copper contents, especially the latter, increase. A detailed investigation (5) by X-ray fluorescence of the composition of over 100 commercial alloys has confirmed that these guidelines are adhered to. As shown in Table II, the gold content was found to decrease significantly from Type I to Type IV alloys while the copper and zinc contents were increasing. The silver content was 
Table I

Composition and Properties of Dental Gold Casting Alloys as Laid Down by the American Dental Association. After (4)

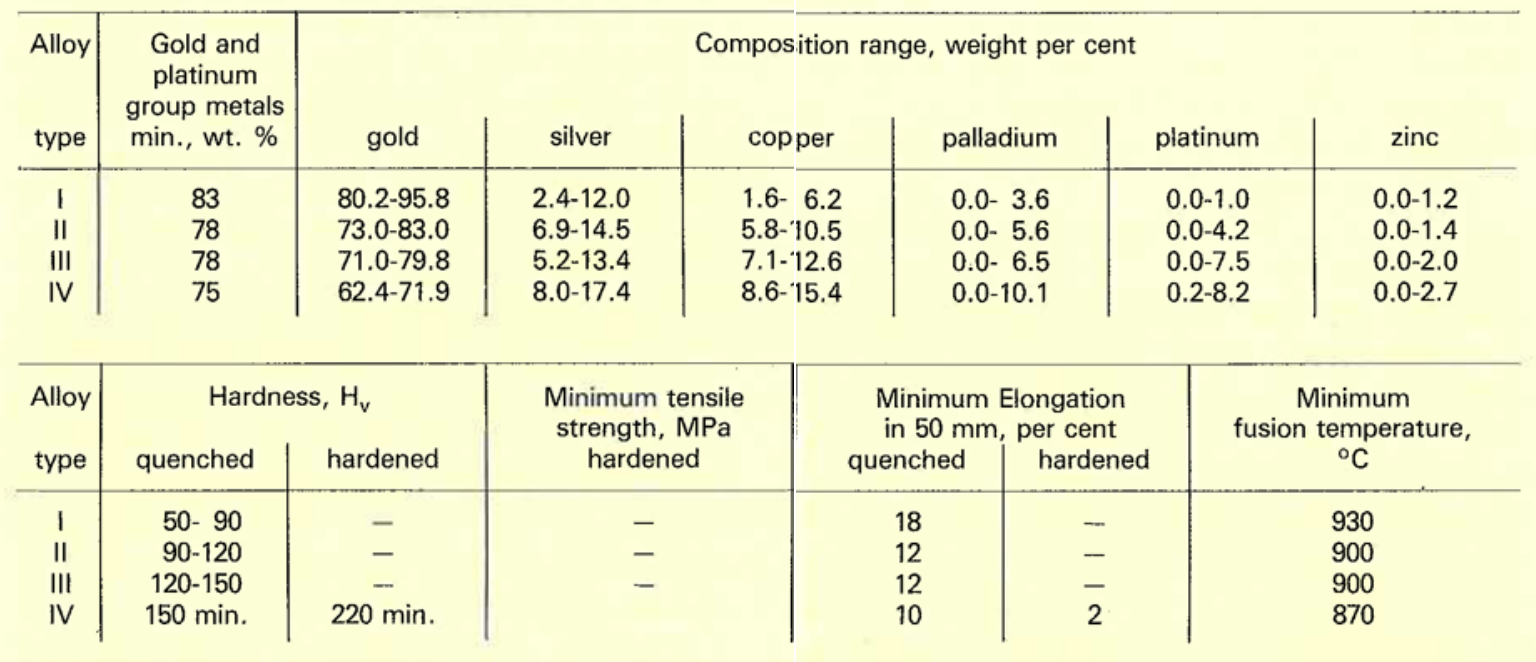

practically identical in all 4 types. The hardest alloys were found to contain about 3 per cent each of platinum and palladium.

From a metallurgical point of view, it is convenient to distinguish between conventional carat gold alloys (ternary gold-silver-copper alloys) with 75 to 90 per cent gold by weight and special alloys of similar basic composition but with minor additions of platinum, palladium and base metals such as iron, indium, tin or zinc (6).

\section{Hardening Mechanisms}

Of the ADA casting gold alloys, only Types III and IV are hardenable from the quenched condition. The extent of this hardening is quantified for Type IV alloys only (Table I).

Since the initial work by Wise (2), age hardening of essentially single phase gold-silver-copper alloys of high gold content is commonly atttributed to the formation of the $\mathrm{AuCu} I$ type superlattice. Yasuda and his co-workers $(7,8)$ have interpreted this effect of superlattice formation in terms of straining of the mother lattice. They have also reported the presence of nodular silver-rich precipitates at the grain boundaries but did not consider that these participate in hardening. Leinfelder and Taylor (9) share these views on the results of precipitation but take into account a second hardening mechanism resulting from the appearance of a fine needle-like structure inside the grains.

Current commercial alloys, however, often have 5 or 6 constituents and it is appropriate to consider the possible contribution to hardening of mechanisms additional to those already defined for the simpler ternary alloys. Thus, detailed studies of thermal ageing,
Table II

Average Composition of Commercial Dental Gold Casting Alloys. After (5)

\begin{tabular}{|c|c|c|c|c|c|c|}
\hline \multirow{2}{*}{$\begin{array}{l}\text { ADA } \\
\text { alloy } \\
\text { type }\end{array}$} & \multicolumn{6}{|c|}{$\begin{array}{l}\text { Average composition, } \\
\text { weight per cent }\end{array}$} \\
\hline & $\mathrm{Au}$ & $\mathrm{Ag}$ & $\mathrm{Cu}$ & $\mathrm{Pt}$ & $\mathrm{Pd}$ & $\mathrm{Zn}$ \\
\hline 1 & 86.1 & 8.6 & 4.2 & 0.2 & 0.7 & 0.2 \\
\hline II & 78.5 & 11.5 & 7.5 & 1.0 & 1.1 & 0.4 \\
\hline III & 76.0 & 9.8 & 9.7 & 2.1 & 1.8 & 0.6 \\
\hline IV & 69.3 & 11.1 & 12.4 & 3.1 & 3.1 & 1.0 \\
\hline
\end{tabular}

first on binary gold-copper alloys and on ternary goldsilver-copper alloys and finally on complex alloys with minor additions, are described here. These were planned with a view to advancing knowledge of the hardening mechanisms operative in multi-component dental casting gold alloys.

\section{The AuCu I Type Superlattice in the Gold- Copper System}

Ordering of the equiatomic gold-copper alloy takes place by relocation of the randomly distributed copper atoms on $\{200\}$ planes. The superlattice then consists of alternate layers of gold and copper atoms. On account of the differing atomic radii of the two elements, this arrangement results in a distortion of the lattice from face centered cubic (f.c.c.) to tetragonal (AuCu I) and eventually orthorhombic $(\mathrm{AuCu} I \mathrm{I})$ form.

Superlattice formation is not a fast phenomenon and ordering with time can easily be monitored. Harker (10) has shown that the following typical $\mathrm{X}$-ray diffraction (XRD) pattern modifications are 
associated with progressive ordering in equiatomic gold-copper samples aged at increasing temperatures from the disordered quenched state:

(1)Loss of intensity of the $\{004\}$ reflection

(2) Broadening of the matrix reflections, except for $\{111\}$ and $\{222\}$, eventually leading to

(3) Splitting of the fundamental peaks as the lattice becomes tetragonal

(4) Appearance of the superlattice peaks of mixed evenness indices.

$\mathrm{XRD}$ also provides information on the changes of lattice parameters, from that of the originally disordered matrix to those of $\mathrm{AuCu}$ I. Correlating these data together with microhardness measurements is a convenient means of assessing the influence of structural changes on mechanical properties. In this manner, it has been shown (11) that when samples of equiatomic gold-copper alloy are aged after quenching from $750^{\circ} \mathrm{C}$, maximum hardness is obtained in 30 minutes at $150^{\circ} \mathrm{C}$ while complete ordering of $\mathrm{AuCu} \mathrm{I}$ requires 30 minutes at $350^{\circ} \mathrm{C}$ (Figure 1). Thus, the hardness of the partially ordered alloy is substantially higher than that achieved at thermodynamic equilibrium. This observation is applicable to alloys partially ordered in 30 minutes below $350^{\circ} \mathrm{C}$ and, to a lesser extent, to alloys partially disordered in 30 minutes above that temperature. Thus, similar effects, although minimized and of lesser practical interest, are observed around $400^{\circ} \mathrm{C}$. They can be attributed to the $\mathrm{AuCu}$ I $\rightarrow \mathrm{AuCu}$ II transformation (Figure 1).

\section{Hardening of Gold-Silver-Copper Ternary Alloys}

The binary edges of the gold-silver-copper system (12) comprise two complete solid solution systems gold-silver and gold-copper - and one eutectic system - silver-copper. The ternary system itself features a miscibility gap, the boundaries of which have been extensively studied and reported upon $(2,13,14)$. In contrast, information on the existence of AuCu-type ordering in ternary alloys is much more fragmentary and often contradictory. Raub (15) observed superlattice XRD peaks on alloys containing up to 30 per cent silver while Hultgren and Tarnapol (16) found that the first 5 per cent addition of silver lowers the ordering temperature by as much as $65^{\circ} \mathrm{C}$.

In order to obtain first hand information, the following alloys were prepared for investigation:

\begin{tabular}{ccrr} 
Alloy & \multicolumn{3}{c}{ Composition, atomic per cent } \\
Designation & $\mathrm{Au}$ & $\mathrm{Ag}$ & $\mathrm{Cu}$ \\
1 & 58 & 7 & 35 \\
2 & 60 & 15 & 25 \\
3 & 64 & 23 & 13
\end{tabular}

These three compositions were selected on account of their potential for phase separation when annealed after quenching. The two phases in thermodynamic equilibrium at the lower temperatures are respectively a silver-rich gold-copper solid solution and a copper-rich gold-silver solid solution. Furthermore, ordering similar to that observed in AuCu may be expected in alloys (1 and 2) and phases rich in copper and gold.

Both dilatometric and XRD measurements were used to monitor thermal ageing in alloys 1 to 3 .

\section{Dilatometric Measurements}

Figure 2 shows the temperature-rise dilatometric curves obtained by thermal cycling of initially quenched samples of alloys 1 to 3 between room temperature and elevated temperatures in the solid solubility domain. A curve obtained under similar conditions on the equiatomic gold-copper alloy is also reported on Figure 2. All four curves show:

- quasi-linear dilatation in a restricted lower temperature range

- changes in slope at intermediate temperatures

- linear dilatation at elevated temperatures.

The overall thermal expansion of the ternary alloys increases together with their copper content. The linear upper portion of the curves corresponds to the disordered solid solution which exists above a temperature dependent upon the composition of each alloy. The temperature range where the curves exhibit an increased slope corresponds to

$$
\text { order } \rightleftarrows \text { disorder }
$$

and/or

$$
\text { single phase } \rightleftarrows \text { two-phase }
$$

transformations. The extent of this range increases as the alloy composition becomes closer to $50 \mathrm{gold} / 50$ copper atomic per cent.

Dilatometry is a dynamic recording technique. It is therefore unsuitable for the precise determination of transformation temperatures. However, the technique is accurate enough to reveal a relationship between copper content and transformation temperatures in gold-silver-copper alloys. Figure 3 shows that this relationship is linear when both the starting and finishing temperatures of transformations (on heating) are considered. In the equiatomic binary alloy, starting and finishing temperatures are respectively 235 and $415^{\circ} \mathrm{C}$ which is in good agreement with results on ordering obtained by other techniques (Figure 1).

\section{Phase Identification}

In a study of 75 gold $/ x$ silver/y copper weight per cent alloys, McMullin and Norton (13) reported that upon cooling from the high temperature single phase domain, the lattice parameter of the solid solution decreased and a second f.c.c. lattice appeared with a parameter corresponding to that of a silver-rich phase. 


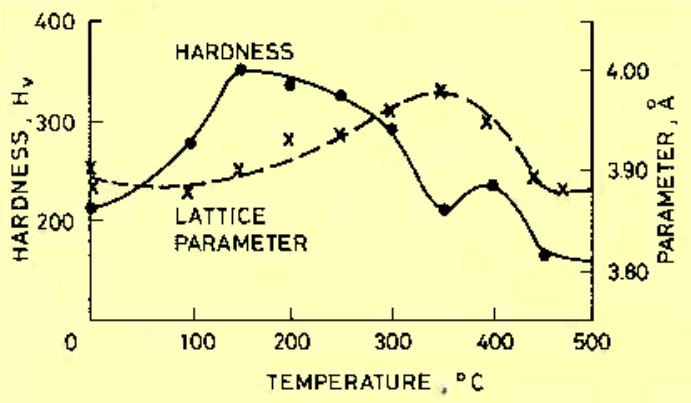

Fig. 1 Lattice parumeter and hardness of the equiatomic gold-copper alloy after 30 minules thermal ageing at temperatures between 100 and $500^{\circ} \mathrm{C}$. All the samples were initislly annealed 30 minutes at $750^{\circ} \mathrm{C}$ and quenched in water. The two maxima in the hardness curve correspond to incomplete disorder $\rightarrow$ AuCu I and AuCu I $\rightarrow$ AuCu II transformations

Table III

Composition of Complex Dental Gold Alloys Used in this Study

\begin{tabular}{|c|c|c|c|c|c|c|}
\hline \multirow{2}{*}{$\begin{array}{l}\text { Alloy } \\
\text { desig- } \\
\text { nation }\end{array}$} & \multicolumn{6}{|c|}{$\begin{array}{l}\text { Composition, } \\
\text { weight per cent }\end{array}$} \\
\hline & Au & $\mathrm{Ag}$ & Cus & $P_{t}$ & Pd & $Z_{n}$ \\
\hline A & 73.0 & 13 & 10 & 3 & 0 & 1 \\
\hline B & 75.5 & 15 & 4.8 & 2.2 & 2.5 & 0 \\
\hline C & 74.0 & 14.7 & 4.7 & 2.2 & 2.4 & 2 \\
\hline
\end{tabular}

A similar phenomenon was recorded on alloys with 58 per cent gold, thus confirming earlier results by Pickus and Pickus (17) who had noted that upon thermal ageing, hardening could be measured prior to micrographic evidence of phase separation.

In the work reported here, micrography and XRD on alloys 1 to 3 after quenching from elevated temperature $\left(850^{\circ} \mathrm{C}\right)$, confirmed the existence of an f.c.c. solid solution of increasing lattice parameter with increasing silver content $(a=3.95,3.96$ and $4.03 \AA$ A respectively for alloys 1,2 and 3). After ageing at temperatures within the transformation range as indicated by Figure 3, XRD revealed the coexistence of two phases, one tetragonal ( $a=4.0 \AA$ ) corresponding to an ordered copper-rich phase and the other f.c.c. ( $a=4.2 \AA)$ corresponding to a silver-rich phase.

Thus, two mechanisms can contribute to hardening in ternary gold-silver-copper alloys during thermal ageing, namely:

(1) Decomposition of the f.c.c. solid solution which is stable at high temperature into silver-rich and copper-rich phases, as predicted by the diagram

(2) AuCu I-type ordering in the copper-rich phase.

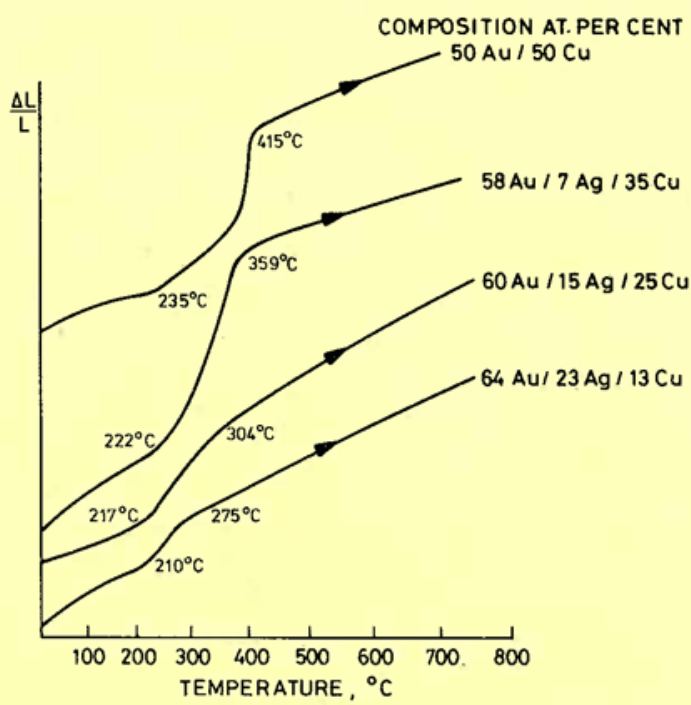

Fig. 2 Temperature-rise dilatometric curves of the equiatomic gold-copper alloy and of three experimental gold-silver-copper ternary alloys. The temperatures are indicated at which the slopes of the curves change markedly, thus revealing the start or the end of ordering and/or phase separation

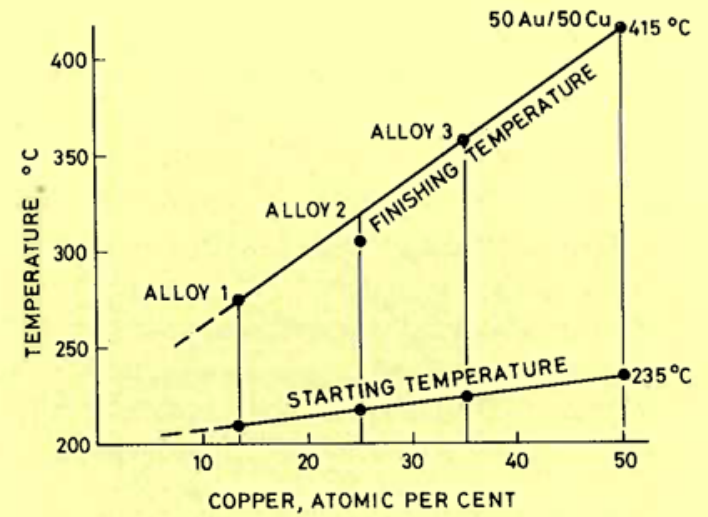

Fig. 3 Relationship between the starting and finishing temperatures of ordering and/or phase separation transformations in gold-(silver)-copper alloys and their copper content (atomic per cent)

\section{Ageing of Industrial Alloys}

Although ternary gold-silver-copper alloys have excellent castability, their mechanical properties may fall short of requirements for cast dental restorations. In order to meet the specifications for ADA Types III and IV alloys, platinum- or palladium-containing formulations have been developed. After ageing, these complex alloys are harder than the corresponding ternary alloys.

\section{Compositions Investigated}

Three compositions, as detailed in Table III, were investigated. Alloy $\mathrm{A}$ is palladium-free and has a 


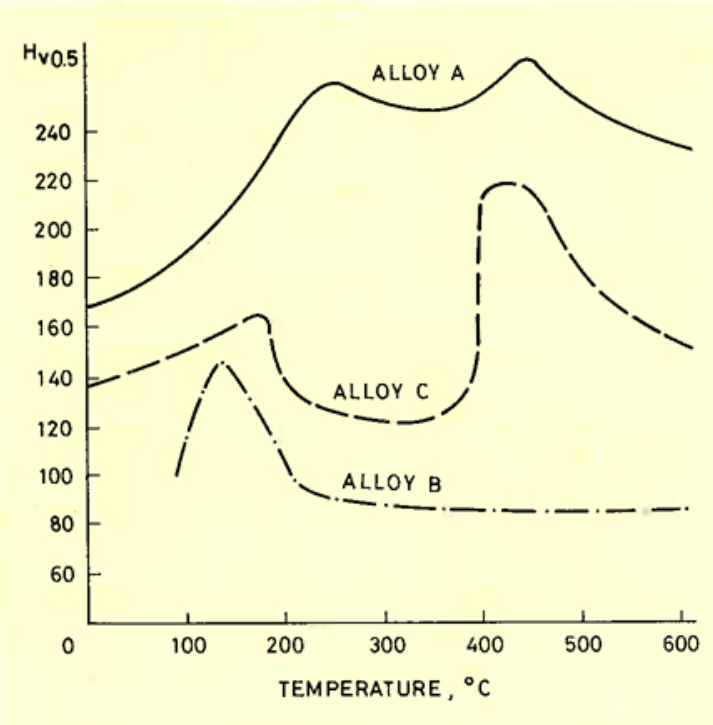

Fig. 4 Microhardness $\left(\mathrm{H}_{\mathrm{v}} 0.5\right)$ of complex alloys A, B and $C$ after 30 minutes thermal ageing at temperatures between 100 and $600^{\circ} \mathrm{C}$. All the samples were initially homogenized 90 minutes at $850^{\circ} \mathrm{C}$ and quenched in water

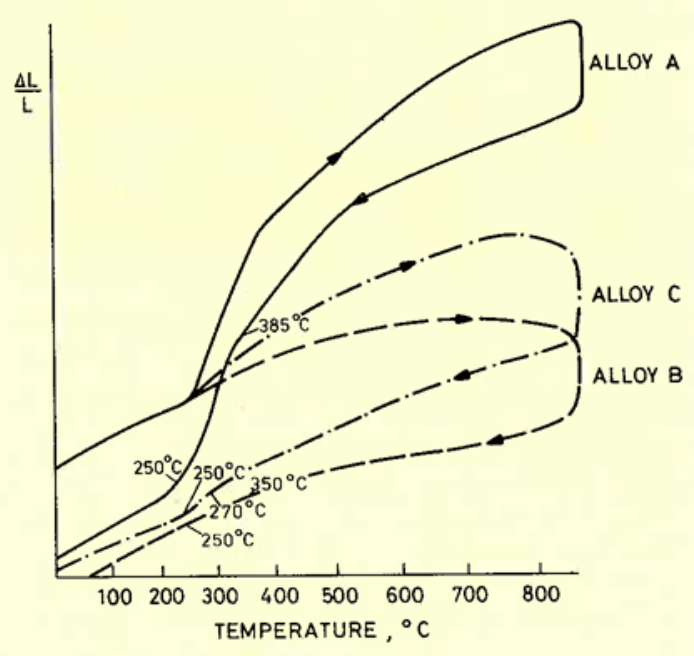

Fig. 5 Dilatometric curves of complex alloys A, B and $C$ recorded during thermal cycling between room temperature and $850^{\circ} \mathrm{C}$

Table IV

Compositions of Matrix Grains and Precipitate in Alloy C as Determined by EPMA After Ageing at $400^{\circ} \mathrm{C}$

\begin{tabular}{l|c|c|c|c|c|c}
\hline & \multicolumn{5}{|c}{ Composition, } \\
& \multicolumn{5}{|c}{ weight per cent } \\
& $\mathrm{Au}$ & $\mathrm{Ag}$ & $\mathrm{Cu}$ & $\mathrm{Pt}$ & $\mathrm{Pd}$ & $\mathrm{Zn}$ \\
\cline { 2 - 7 } & & & & & & \\
Matrix & 77.77 & 12.8 & 5.35 & 2 & 2.50 & 2.33 \\
Precipitate & 74.61 & 13.5 & 5.15 & 2 & 3.11 & 2.23
\end{tabular}

lower gold and a higher copper content than alloy B. These two complex alloys are intended for cast dental restorations and correspond respectively to ternary alloys 1 and 3 which are discussed above. Alloy $C$ is intended for applications where cold-workability and a lower melting point are required. Its composition is similar to that of alloy $B$, except for the addition of some zinc.

Preliminary micrographic work on alloy B showed that as-cast samples exhibit a strongly heterogeneous structure with dendrites oriented parallel to a limited number of directions. Whereas an extended high temperature anneal $\left(24\right.$ hours at $\left.900^{\circ} \mathrm{C}\right)$ resulted in an equiaxed equilibrium structure, it also led to grain coarsening, a feature detrimental to mechanical properties. Annealing for 90 minutes at $850^{\circ} \mathrm{C}$, followed by quenching in water, was found to homogenize the composition without grain growth. Electron probe microanalysis (EPMA) confirmed that little segregation remained after annealing. This treatment was adopted as a standard procedure to produce samples in a suitable condition for further investigation.

\section{Hardening Characteristics}

Following the standard anneal of 90 minutes at $850^{\circ} \mathrm{C}$, alloys $\mathrm{A}, \mathrm{B}$ and $\mathrm{C}$ were submitted to ageing for 30 minutes at temperatures ranging between 100 and $850^{\circ} \mathrm{C}$. The results of hardness measurements after ageing at temperatures up to $600^{\circ} \mathrm{C}$ are plotted on Figure 4. At lower temperature, the hardening behaviour of the three complex alloys was similar to that observed in binary (Figure 1) and ternary (11) alloys. However, with the zinc-containing alloy $\mathrm{C}$, a very prominent second hardness peak was recorded around $400^{\circ} \mathrm{C}$. Isothermal anneals of duration 20 to 90 minutes at this temperature confirmed that maximum hardening of this alloy was achieved in 30 minutes.

\section{Transformations}

The dilatometric curves of alloys $A, B$ and $C$ (Figure 5) recorded during cycling between room temperature and $850^{\circ} \mathrm{C}$ showed the same basic features as those reported for the binary and ternary alloys (Figure 2). The amplitude of the transformations increased with copper content and the curve for alloy A compared well with that for the equiatomic gold-copper alloy. The transformations were less marked in the case of the zinc-containing alloy $\mathrm{C}$ and even less so with alloy B. Lastly, the transformation temperatures of complex alloys were higher than those of gold-silver-copper alloys.

$\mathrm{XRD}$ monitoring of ageing in alloy $\mathrm{C}$ at increasing temperature showed the appearance of additional peaks, presumably corresponding to an AuCu-type superlattice. More remarkably, optical microscopy of 
Fig. 6 Precipitation at the grain boundaries of the zinccontaining complex alloy $\mathrm{C}(\mathbf{7 4 . 0}$ gold $/ 14.7$ silver $/ 4.7$ copper $/ 2.2$ platinum $/ 2.4$ palladium $/ 2$ zinc, weight per cent) after ageing at $400^{\circ} \mathrm{C}$ and slow cooling

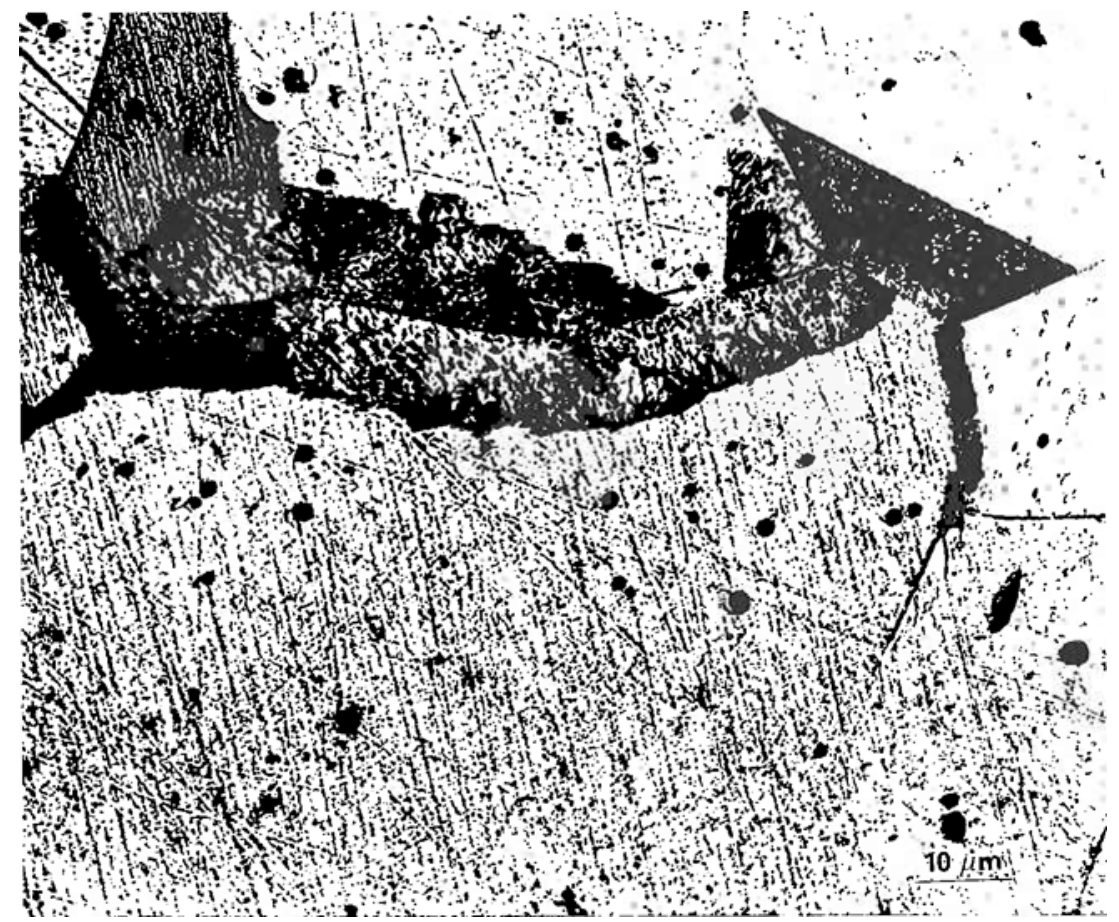

samples aged at $380^{\circ} \mathrm{C}$ and above revealed the growth of precipitates, initially at grain boundaries (Figure 6) but progressively throughout the grains. EPMA failed to detect major differences of composition between the precipitates and the matrix (Table IV).

Thus, below $380^{\circ} \mathrm{C}$ the thermal hardening mechanism in complex commercial alloys is similar to that identified in 50 gold $/ 50$ copper and in goldsilver-copper alloys and also involves a contraction of the solid solution lattice parameter. Above $380^{\circ} \mathrm{C}$, a second hardening phenomenon takes place which is far more effective than that measured on the binary alloy and which does not exist in ternary alloys. It must be concluded that this latter phenomenon, together with the separation of a second phase, corresponds to a mechanism of a new nature (11).

\section{The Role of Zine}

The different behaviours of zinc-free alloy $B$ and zinc-containing alloy $\mathrm{C}$ indicate the possible involvement of this element in the hardening. Further work was therefore undertaken to clarify this point.

Increasing additions of zinc in ternary alloy 3 (64 gold/23 silver/13 copper atomic per cent) led to considerable hardening of the quenched and disordered solution. This effect was most noticeable up to 1.6 weight per cent zinc. Beyond this concentration, little further modification of hardness was measured (Figure 7). XRD monitoring of the lattice parameter showed a contraction of the matrix with increasing zinc content. If zinc was added in excess of 5.8 per cent, the lattice was drastically altered indicating that the limit of solubility of this element was approached. If 2 per cent by weight of each platinum and zinc were added to alloy 3 , superlattice peaks appeared on the XRD patterns. These peaks corresponded to those noted on samples of ternary and complex alloys. Zinc therefore promotes and accelerates both ordering and precipitation during annealing at $400^{\circ} \mathrm{C}$. These two mechanisms are significant with respect to hardening.

The gold-zinc phase diagram (18) indicates that several intermetallic compounds are in equilibrium at

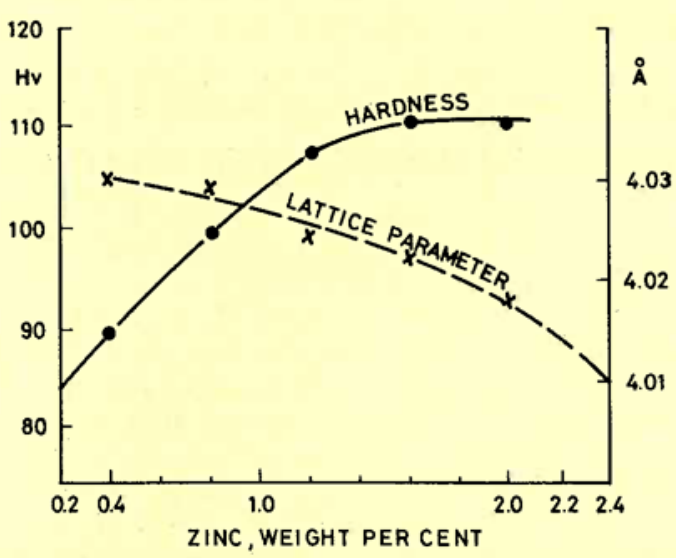

Fig. 7 Lattice parameter and hardness of alloy 3 quenched from $850^{\circ} \mathrm{C}$ as a function of the percentage of zinc added to the basic composition (64 gold/23 silver/13 copper, atomic per cent) 
$400^{\circ} \mathrm{C}$. Depending upon the zinc concentration (by weight) these can be:

- AuZn, between 21 and 29 per cent

- AuZn ${ }_{3}$, between 37 and 55 per cent

- A primary hexagonal close packed zinc-gold phase, between 95 and 100 per cent.

These compounds can be observed as well defined layers after treatment at $400^{\circ} \mathrm{C}$ of a diffusion couple made from the two pure metals. For the present work, diffusion couples made of pure zinc and alloys 3 and $\mathrm{B}$ were annealed at $400^{\circ} \mathrm{C}$. The microhardness of the layers which developed closest to the gold alloy were measured and EPMA determinations were carried out. The first gold-rich layer in the zinc-alloy 3 couple was found to be harder than the alloy $\left(\mathrm{H}_{\mathrm{v}}=188\right.$, as opposed to 80 ) and to consist of 91 gold $/ 5$ silver $/ 2$ copper/2 zinc weight per cent which is close to $\mathrm{Au}_{3} \mathrm{Zn}$. In the zinc-alloy $\mathrm{B}$ couple, the first layer was very much harder than the alloy $\left(\mathrm{H}_{\mathrm{v}}=390\right)$ and consisted of $45 \mathrm{gold} / 2$ silver $/ 3$ copper $/ 50$ zinc weight per cent, a composition close to that of $\mathrm{AuZn}_{3}$.

These observations were amplified by EPMA determinations of the composition of the precipitate observed in complex alloys and in the platinum- and zinc-modified ternary alloys after ageing at $400^{\circ} \mathrm{C}$. As mentioned earlier, the composition of this precipitate was very close to that of the matrix (Table IV). This result is indicative of hardening by a martensitic transformation without diffusion.

It is thus possible to define the promotion of hardening in the presence of zinc in terms of (a) the precipitation of an $\mathrm{Au}_{3} \mathrm{Zn}$-type phase and (b) $\mathrm{AuCu}$ type ordering by shearing of the original lattice. The two phenomena are difficult to distinguish because at $400^{\circ} \mathrm{C}$ the lattices of both phases are closely similar.

\section{Conclusion}

The results of this study point to complex mechanisms being involved in the hardening of dental casting gold alloys. Depending upon the heat treatment schedules adopted and the nature of minor additions in the alloys, ordering and/or intermetallic compound formation can be induced and lead to hardening. Scope therefore exists for devising accurate heat treatment programmes for alloys incorporating minor hardening additions, which will produce gold-based dental casting alloys of great promise.

\section{References}

1 R. L. Coleman, 7. Res. N.B.S., 1928, 1, 867-938

2 'Gold: Recovery, Properties and Applications', ed. by E. M. Wise, D. van Nostrand Co. Inc., Princeton, 1964

3 J. P. Nielsen and J. J. Tucillo, F. Dent. Res., 1966, 45, 964-969

4 'Guide to Dental Materials and Devices', American Dental Association, 7th Edition, 1974-1975

5 J. D. Eick, H. J. Caul, T. Hegdahl and G. Dickson, f. Dent. Res., 1969, 48, 1284-1289

6 M. F. Meyer, Rev. Fr. Odontol. Stomatol, 1967, 2, 1376

7 Y. Kanzawa, K. Yasuda and H. Metahi, f. Less-Common Met., $1975,4,121-128$

8 K. Yasuda and Y. Kanzawa, Trans. Jpn. Inst. Met., 1977, 18, (1), 46-54

9 K. Leinfelder and D. F. Taylor, F. Dent. Res., 1977, 56, (3), 335-345

10 D. Harker, Trans. Am. Soc. Met., 1944, 32, 210

11 J.-J. Labarge, D. Tréheux and P. Guiraldenq, Mém. Sci. Rev. Metall., 1976, 73, (2), 141-148

12 A. S. McDonald and G. H. Sistare, Gold Bull., 1978, 11, (3), 66-73

13 J. G. McMullin and J. T. Norton, Trans. Am. Inst. Min. Metall. Eng., 1949, 185, 46-48

14 E. F. I. Roberts and K. M. Clarke, Gold Bull., 1979, 12, (1) 9.19

15 E. Raub, P. Walter and A. Engel, Z. Metallkd., 1949, 40, (11), 401-405

E. Raub, Z. Metallkd., 1949, 40, 47-54

16 R. Hultgren and L. Tarnapol, Trans. Am. Inst. Min. Metall. Eng., 1939, 133, 228-237

17. M. R. Pickus and I. W. Pickus, Met. Technol., 1943, 10, 1-7

$18 \mathrm{M}$. Hansen and K. Anderko, 'Constitution of Binary Alloys', 2nd Edition, McGraw Hill Book Co. Inc., New York, 1958, p. 241-244 